Check for updates

Cite this: RSC Adv., 2017, 7, 19948

Received 24th January 2017

Accepted 28th March 2017

DOI: $10.1039 / \mathrm{c} 7 \mathrm{ra01045a}$

rsc.li/rsc-advances

\title{
Visible light mediated cyclization of tertiary anilines with maleimides using a supported iridium complex catalyst $\uparrow$
}

\author{
Feng Peng, ${ }^{\text {a }}$ Peng Zhi, ${ }^{a}$ Heng Ji, ${ }^{\text {ab }}$ Huan Zhao, ${ }^{a}$ Fen-Ying Kong, ${ }^{b}$ \\ Xue-Zheng Liang (D) ${ }^{* a}$ and Yong-Miao Shen (D) *a
}

\begin{abstract}
The novel supported iridium complex catalyst was synthesized through the immobilization of the iridium complex onto vinylpyridine and divinylbenzene copolymer. In order to avoid the iridium releasing, vinylpyridine was used to provide the chelating sites. The catalytic activity was investigated through the visible light mediated cyclization of tertiary anilines and maleimides. The catalyst showed high activity and stability with the average isolated yield over $50 \%$. The heterogeneous process greatly simplified catalyst recovery and product purification, which was quite superior to homogeneous iridium complexes. Compared with transition metal complexes such as $\mathrm{Ru}(\mathrm{bpy})_{3} \mathrm{Cl}_{2}$ or $\operatorname{Ir}(\mathrm{ppy})_{2}(\mathrm{dtbbpy}) \mathrm{PF}_{6}$, advantages of this supported iridium complex catalyst as the photocatalyst include high hydrophobic BET surface and catalytic activity, low cost, ease of recovering and being able to be used for at least four times without significant decay of catalytic activity.
\end{abstract}

\section{Introduction}

Visible light mediated photoredox catalysis, mostly centered on ruthenium (Ru)- and iridium (Ir)-based photoredox catalysts, is an effective and versatile method for inert $\mathrm{C}-\mathrm{H}$ bond activation and functionalization. ${ }^{1-9}$ In particular, the direct couplings of $\mathrm{sp}^{3} \mathrm{C}-\mathrm{H}$ bonds adjacent to a tertiary nitrogen atom has attracted increasing attention in recent years. ${ }^{10-12}$ The cyclization of tertiary anilines and maleimides was the typical visible light mediated reaction, in which the inert $\mathrm{C}-\mathrm{H}$ bond interacted with a vinyl group to form the cyclic product in one step. ${ }^{13-23}$ This transformation could be realized by using $\mathrm{Ru}(\mathrm{bpy})_{3} \mathrm{Cl}_{2}{ }^{13}$ or $\operatorname{Ir}(\mathrm{ppy})_{2}(\mathrm{dtbbpy}) \mathrm{PF}_{6}{ }^{13}$ or $\left[\mathrm{Cu}(\mathrm{dap})_{2}\right] \mathrm{Cl}^{16}$ as a photocatalyst. However these transition metal complexes suffer from the drawbacks of high cost, difficult recovery and an inability to be reused. We wondered whether these cyclization reactions can be achieved in a more environmentally benign way with an inexpensive heterogeneous catalyst that can easily be isolated after the reaction. ${ }^{23-27}$

Recently much attention was taken on implementing visible-light photoredox catalysis with heterogeneous catalysts. $\mathrm{TiO}_{2}$ and related semiconductors are used as the common

${ }^{a}$ Key Laboratory of Clean Dyeing and Finishing Technology of Zhejiang Province, School of Chemistry and Chemical Engineering, Shaoxing University, Shaoxing 312000, China. E-mail: liangxuezheng@126.com; shenyongmiao@usx.edu.cn

${ }^{b}$ School of Chemistry and Chemical Engineering, Yancheng Institute of Technology, 224051, China

$\dagger$ Electronic supplementary information (ESI) available. See DOI: $10.1039 / \mathrm{c} 7 \mathrm{ra} 01045 \mathrm{a}$ heterogeneous photocatalysts. ${ }^{28,29}$ Only a few immobilized photosensitizers catalysts were reported due to the mass transfer hindrance and light adsorption efficiency. ${ }^{30-33}$ The solid supports were very important for the immobilization. The cheap commercial silica gel with high surface area was the most used and various supported catalysts were developed. ${ }^{34}$ However, for the photocatalyst, not only the high BrunnerEmmet-Teller (BET) surface area but also the light adsorption efficiency was the key factor. Here, silica gel could hardly act as supported. $\mathrm{TiO}_{2}$ was the widely-used photocatalyst and various light mediated reactions were developed using the efficient catalyst. However, the complicated modification of $\mathrm{TiO}_{2}$ was carried out to bring certain chelating sites for immobilization. In addition, the low BET surface area of the nano $\mathrm{TiO}_{2}$ greatly affected the catalytic activities of the resulting supported catalysts. Compared to the inorganic supports, the organic polymer owned the high affinity with reaction mixture..$^{35}$ Furthermore, the chelating sites could be easily introduced and evenly dispersed via the simple copolymerization. The nano porous polydivinylbenzene (PDVB) with superhydrophobicity and superoleophilicity was widely used as support. ${ }^{36,37}$ Our group grafted the acidic ionic liquids onto the PDVB and applied to biodiesel synthesis from waste oils. ${ }^{35}$ Despite the significant advantages of supported complex catalyst, the synthesis and use of them in $\mathrm{C}-\mathrm{H}$ bond activation and $\mathrm{C}-\mathrm{C}$ and C-heteroatom bond formation are still quite limited. ${ }^{38-45}$ Here the novel supported iridium complex catalyst was synthesized by the immobilization of the iridium onto the pyridine modified PDVB (Scheme 1). Iridium was chelated with pyridine, which confirmed the strong interaction between active sites 

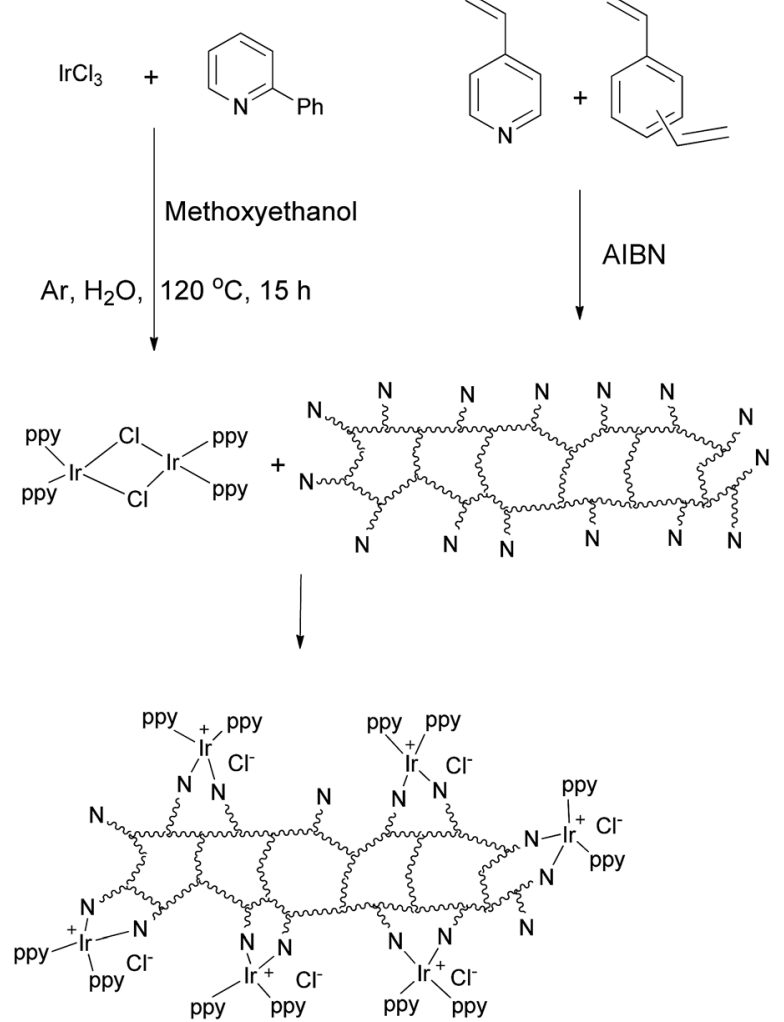

Scheme 1 The synthetic route of the supported iridium complex.

and the support, resulting in high stability. The copolymer owned high BET surface area, which benefited the mass transfer process and accessible active sites. The organic framework ensured the high affinity with the organic reactants and the abundant aromatic structure also confirmed the sensitive visible light adsorption. We found that this novel catalyst showed high activity for the photo mediated cyclization of tertiary anilines and maleimides with additional advantage of easy recovery.

\section{Experimental}

\subsection{Synthesis of the supported iridium complex catalyst}

2.1.1 Synthesis of the iridium complex. $\mathrm{IrCl}_{3}(0.8 \mathrm{mmol}$, $0.28 \mathrm{~g})$ and 2-phenylpyridine $(1.8 \mathrm{mmol}, 0.28 \mathrm{~g})$ were dissolved in the mixture of $30 \mathrm{~mL}$ 2-methoxyethanol and $10 \mathrm{~mL}$ water. The solution was stirred at $120^{\circ} \mathrm{C}$ for $15 \mathrm{~h}$ under argon atmosphere. After filtering, washing and vacuum drying at $60^{\circ} \mathrm{C}$ for $12 \mathrm{~h}$, the iridium complex was obtained with the yield of $70 \%(0.60 \mathrm{~g})$.

2.1.2 Synthesis of the polymer support. 4-Vinylpyridine (Vpy) (range from $0.1 \mathrm{~g}$ to $0.5 \mathrm{~g}$ ), divinylbenzene $(2.0 \mathrm{~g}, 15.38$ mmol), 2,2'-azobisisobutyronitrile (AIBN, $0.01 \mathrm{~g}$ ) and $20 \mathrm{~mL}$ ethyl acetate were mixed and stirred for $2 \mathrm{~h}$ at room temperature to form the homogeneous solution. Then, the solution was transferred to the stainless-steel autoclave and solvothermally treated at $100{ }^{\circ} \mathrm{C}$ for $24 \mathrm{~h}$. The obtained solid was filtered and washed with acetone. The copolymer was obtained after drying at $80{ }^{\circ} \mathrm{C}$ in an oven for $12 \mathrm{~h}$ with the yield over $95 \%$.
2.1.3 Synthesis of the supported iridium complex. Iridium complex $(0.076 \mathrm{~g})$ and 2.0 equiv. of copolymer (calculated with the molar amount of pyridine, the content of pyridyl moiety in the copolymers was determined by elemental analysis) were mixed in $10 \mathrm{~mL}$ glycol. The mixture was stirred at $150^{\circ} \mathrm{C}$ for $2 \mathrm{~h}$ under argon atmosphere. Then, after cooling to room temperature, the celadon powder was filtered, washed and dried in a vacuum oven at $50{ }^{\circ} \mathrm{C}$ for $24 \mathrm{~h}$ to afford the supported catalyst.

\subsection{The cyclization of tertiary anilines and maleimides}

Tertiary anilines $1(1 \mathrm{mmol})$ and maleimides $2(0.5 \mathrm{mmol})$ and catalyst P4 (iridium content is $1.2 \mathrm{~mol} \%$ of $2(0.0048 \mathrm{~g})$ ) were dissolved in $20 \mathrm{~mL}$ NMP. The reaction mixture was stirred beside a $3 \mathrm{~W}$ blue LED lamp with an edge to edge distance of $2 \mathrm{~cm}$ for irradiation. After the reaction was completed, the catalyst was recovered by centrifugal filtration, and then the reaction mixture was poured into $30 \mathrm{~mL}$ water. The aqueous layer was extracted with EtOAc $(15 \mathrm{~mL} \times 3)$. The combined organic layers were dried with anhydrous $\mathrm{MgSO}_{4}$. The solvent was removed under reduced pressure, and the crude mixture was directly charged on silica gel and purified by column chromatography with petroleum ether/ethyl acetate as eluents (gradient elution).

\section{Results and discussion}

\subsection{Characterization of the supported iridium complex}

The active sites were the key factor for high activities, so the iridium loading amount was investigated first. The copolymer with different Vpy amounts was synthesized and reacted with iridium complex to give four different catalysts. The iridium content was increased with the increase of pyridine content, while the BET surface area decreased greatly. The hypercrosslinked structure was destroyed by the Vpy and the bulky iridium complex were the main reason for the surface area decrease. Iridium content increased from $5.34 \%$ to $7.54 \%$ with the increase of pyridine content from $3.58 \%$ to $17.80 \%$. The pyridine amount was much more than the iridium, this indicated that some pyridine sites were not occupied by iridium. Not all the pyridine molecules were chelated by iridium complex. For the bulky iridium molecules, they could hardly approach the pyridine inside some micropores, which might increase the difficulty of chelating reaction. Also these results indicated that the chelation process occurred on the more active sites in the beginning. The chelated Ir-complex had certain effect on the following process, which might cause by the steric hindrance. The late Ir complex could hardly occupy the pyridine molecules next to the chelated sites. As a result, the Ir content much lower than the pyridine content. The bidentate chelated structures formed with pyridine content, which could provide more active site for the complex. The catalytic activity of different polymers was investigated through cyclization of $\mathrm{N}, \mathrm{N}$ dimethylaniline with $N$-phenylmaleimide (Table 1). The amounts of all these used catalysts (P1-P4) were calculated based on the molar amounts of iridium. That is we use the same iridium molar amount as the reaction catalyst. 
Table 1 The effect of the different amounts of iridium loading ${ }^{a}$

\begin{tabular}{lllll}
\hline $\begin{array}{l}\text { Catalyst (Vpy } \\
\text { amount/g) }\end{array}$ & $\begin{array}{l}\text { Pyridine } \\
\text { (wt\%) }\end{array}$ & $\begin{array}{l}\text { Iridium }^{b} \\
(\mathrm{wt} \%)\end{array}$ & $\begin{array}{l}\text { BET } \\
\left(\text { surface } / \mathrm{m}^{2} \mathrm{~g}^{-1}\right)\end{array}$ & Yield/\% \\
\hline P1 (0.1) & 3.58 & 5.34 & 865 & 82 \\
P2 (0.2) & 7.16 & 5.75 & 635 & 84 \\
P3 (0.3) & 10.74 & 6.73 & 342 & 87 \\
P4 (0.5) & 17.80 & 7.54 & 246 & 89
\end{tabular}

${ }^{a}$ Reaction condition: a mixture of $1 \mathrm{a}(0.0303 \mathrm{~g}, 0.25 \mathrm{mmol}), 2 \mathrm{a}(0.0216 \mathrm{~g}$, $0.125 \mathrm{mmol})$ and catalyst $(0.0014 \mathrm{~g})$ in the solvent $(5 \mathrm{~mL})$ was irradiated with a $3 \mathrm{~W}$ blue LED lamp in the air for $12 \mathrm{~h}$. ${ }^{b}$ Calculated by the inductively coupled plasma-atomic emission spectroscopy (ICP-AES).

The results showed that the $\mathrm{P} 4$ catalyst with the highest iridium content has relatively high catalytic activity. P4 owned both high BET surface area and iridium amount, which confirmed the sufficient easily accessible active site for the reaction. The usage of the heterogeneous catalyst $\mathrm{P} 4$ was only need 1.2 mol\% (calculated by iridium content) to realize this transformation with a yield of $89 \%$. For the transition metal complexes such as $\mathrm{Ru}(\mathrm{bpy})_{3} \mathrm{Cl}_{2}{ }^{13}$ or $\operatorname{Ir}(\mathrm{ppy})_{2}(\mathrm{dtbbpy}) \mathrm{PF}_{6}{ }^{13}$ normally need 3.5 $\mathrm{mol} \%$ of catalyst to get the same result which was also proved the high activity of the synthesized catalyst $\mathrm{P} 4$.

Next the leaching studies were tested also proved that the stability of the catalyst. We used three kinds of solvents $(\mathrm{N}$ methyl-2-pyrrolidone (NMP), ethanol and acetone). P4 catalyst was added to the $5 \mathrm{~mL}$ solvent and stirred $24 \mathrm{~h}$, then centrifuged and the supernatant was tested by the ICP-AES. Iridium was not detected in the supernatant. When we use the supernatant as the reaction solvent and irradiated under a $3 \mathrm{~W}$ blue LED lamp for $12 \mathrm{~h}$, no cyclized product was detected. All these results showed the high stability of the P4 catalyst.

The scanning electron microscope (SEM) images of P4 showed the irregular spheres structures, which was quite similar to that of PDVB. ${ }^{\mathbf{2 3 , 2 4}}$ The particle sizes about $20-30 \mathrm{~nm}$ as depicted in Fig. 1.

The small particles gathered together to form the blocks due to the high affinities with obvious boundary. The particles own the uniform structure, which indicated the supporting process was so mild that the copolymer structure could be well kept. The energy disperse spectroscopy (EDS) of P4 further confirmed that Ir-complex was successfully introduced to the copolymer. The EDS also showed that the iridium was evenly dispersed in the surface, which was quite accessible to reactants. P4 owned the cross-linked structures via PDVB, which was very stable in organic solvents and the particle could be well kept during the immobilization process. The cross-linked structure made the recovery of the $\mathrm{P} 4$ quite simple without specified operation except for filtration.

The TEM image of copolymer and P4 also displayed the sphere structures with the diameter about 20-50 nm (Fig. 2).

The structure changed little after immobilization, which further confirmed the high stability of the support. The particles were gathered together, which was similar to SEM. Some duck areas in TEM was the close packed area. The UV-visible absorption spectrum of copolymer and P4 were shown in Fig. 3. Both the copolymer and P4 showed strong adsorption in

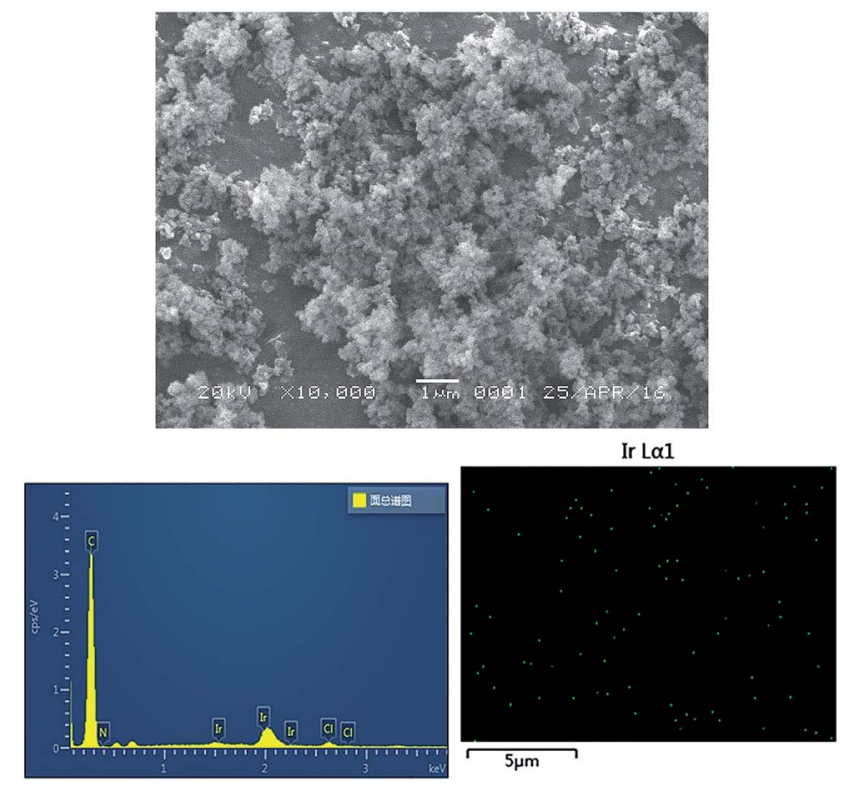

Fig. 1 The SEM images of P4.

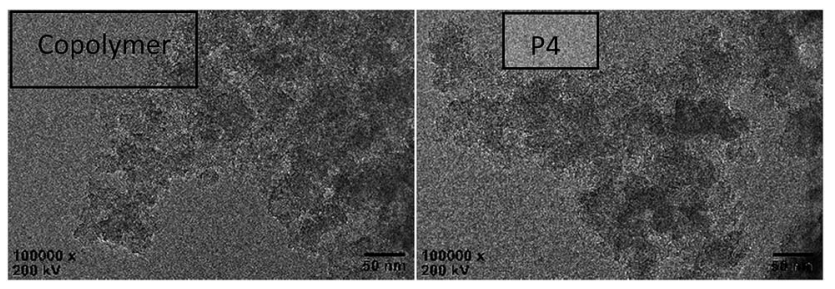

Fig. 2 The TEM images of copolymer and P4.

220 and $265 \mathrm{~nm}$, which assigned to the aromatic ring from pyridine and benzene. P4 also showed obvious adsorption in the visible light area, which indicated that $\mathrm{P} 4$ owned the ability to activate the visible lights mediated reactions.

\subsection{The catalytic activities for the cyclization of tertiary anilines with maleimides}

Initially, the reaction between $N, N$-dimethylaniline (1a) and $N$ phenylmaleimide (2a) was used to optimize of the reaction

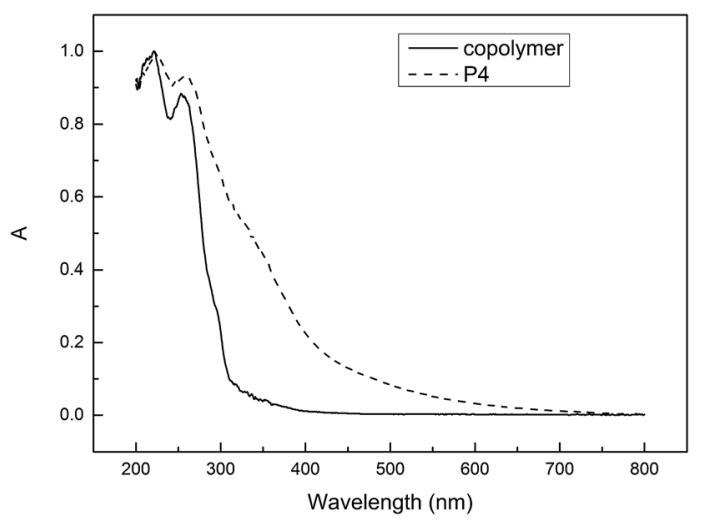

Fig. 3 The UV-visible absorption spectrum of copolymer and P4. 
conditions (Table 2). We found that only $1.2 \mathrm{~mol} \%$ of the catalyst (calculated by iridium content) is needed for effectively bringing the cyclization process. The reactions in different solvents were then examined, and NMP turned out to be the best solvent. Next, we turn our attention to the effect of the molar ratio of $\mathbf{2 a}$ and $\mathbf{1 a}$ and found that when this ratio was adjusted to $1: 1.5$ and $1: 1.2$, the yield of 3a decreased. We have further found that when the reaction was carried out in the absence of air in an argon atmosphere, no product formation can be detected (entry 14). Therefore, we choose the optimized reaction conditions as irradiating maleimide and $\mathrm{N}, \mathrm{N}$-dimethylaniline ( 2 equiv.) in NMP in the presence of P4 (1.2 mol\%) under air.

Next, we examined a series of $N, N$-dimethylanilines 1 and maleimides 2 with a range of substituents on the benzene ring of 1 and the $\mathrm{N}$ atom of 2 (Table 3). We found that $N$-arylmaleimide with electron-donating on the aryl reacted well with $N, N$ dimethylaniline to give the cyclization products in satisfactory yields (entries 2 and 7 ).

To the contrary, when maleimide with electron withdrawing group on the aryl, the yield was poor (entries 3, 4, 8 and 9). Similarly, $N, N$-dimethylanilines also show the same rules (entry 1 vs. entry 6, entry 12 vs. entry 6). We also found that in a few cases, the stability of the compounds turned out to be important for the reaction, such as the reaction of 2-methoxyl- $N, N$ dimethylaniline with 2a led to a much lower product yield (entries 17 and 18).

Table 2 Optimization studies ${ }^{a}$



\begin{tabular}{|c|c|c|c|c|}
\hline Entry & Catalyst/mol\% & $\begin{array}{l}\text { Molar ratio } \\
(\mathbf{2 a}: \mathbf{1 a})\end{array}$ & Solvent & Yield $^{b}(\mathbf{3 a}) / \%$ \\
\hline 1 & 1.2 & $1: 2$ & NMP & 89 \\
\hline 2 & 1.2 & $1: 2$ & DMF & 69 \\
\hline 3 & 1.2 & $1: 2$ & EtOH & 34 \\
\hline 4 & 1.2 & $1: 2$ & DMSO & 51 \\
\hline 5 & 1.2 & $1: 2$ & $\mathrm{CH}_{3} \mathrm{CN}$ & 61 \\
\hline 6 & 1.2 & $1: 2$ & Acetone & 46 \\
\hline 7 & 1.2 & $1: 2$ & DCM & 27 \\
\hline 8 & 1.2 & $1: 2$ & $\mathrm{MeOH}$ & 11 \\
\hline 9 & 1.2 & $1: 1.5$ & NMP & 77 \\
\hline 10 & 1.2 & $1: 1$ & NMP & 66 \\
\hline 11 & 1.2 & $1: 2.5$ & NMP & 88 \\
\hline 12 & 1.0 & $1: 2$ & NMP & 82 \\
\hline 13 & 1.5 & $1: 2$ & NMP & 81 \\
\hline 14 & 1.2 & $1: 2$ & NMP & $\mathrm{ND}^{c}$ \\
\hline
\end{tabular}

${ }^{a}$ Reaction conditions: a mixture of 1a $(0.0303 \mathrm{~g}, 0.25 \mathrm{mmol}), 2 \mathrm{a}$ $(0.0216 \mathrm{~g}, 0.125 \mathrm{mmol})$ and catalyst P4 $(0.0009 \mathrm{~g})$ in the solvent $(5 \mathrm{~mL})$ was irradiated with a $3 \mathrm{~W}$ blue LED lamp in the air for $12 \mathrm{~h}$. ${ }^{b}$ Yield after chromatographic purification. ${ }^{c}$ Reaction in an argon atmosphere.
Table 3 Visible light mediated cyclization of tertiary anilines and maleimides with P4 as photocatalyst ${ }^{a}$

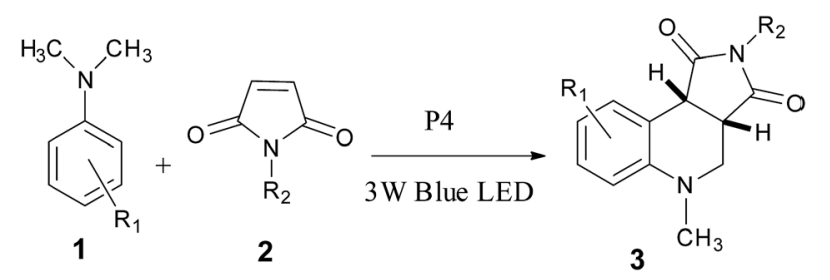

\begin{tabular}{lllllll}
\hline Entry & $\mathrm{R}_{\mathbf{1}}$ & $\mathbf{1}$ & $\mathrm{R}$ & $\mathbf{2}$ & $\mathbf{3}$ & Yield $^{b} \%$ \\
\hline 1 & $\mathrm{H}$ & $\mathbf{1 a}$ & $\mathrm{Ph}$ & $\mathbf{2 a}$ & $\mathbf{3 a}$ & 72 \\
2 & $\mathrm{H}$ & $\mathbf{1 a}$ & $4-\mathrm{MePh}$ & $\mathbf{2 b}$ & $\mathbf{3 b}$ & 87 \\
3 & $\mathrm{H}$ & $\mathbf{1 a}$ & $4-\mathrm{FPh}$ & $\mathbf{2 c}$ & $\mathbf{3 c}$ & 50 \\
4 & $\mathrm{H}$ & $\mathbf{1 a}$ & $4-\mathrm{ClPh}$ & $\mathbf{2 d}$ & $\mathbf{3 d}$ & 59 \\
5 & $\mathrm{H}$ & $\mathbf{1 a}$ & $\mathrm{Bn}$ & $\mathbf{2 e}$ & $\mathbf{3 e}$ & 52 \\
6 & $4-\mathrm{Me}$ & $\mathbf{1 a}$ & $\mathrm{Ph}$ & $\mathbf{2 f}$ & $\mathbf{3 f}$ & 86 \\
7 & $4-\mathrm{Me}$ & $\mathbf{1 a}$ & $4-\mathrm{MePh}$ & $\mathbf{2 g}$ & $\mathbf{3 g}$ & 89 \\
8 & $4-\mathrm{Me}$ & $\mathbf{1 a}$ & $4-\mathrm{FPh}$ & $\mathbf{2 h}$ & $\mathbf{3 h}$ & 62 \\
9 & $4-\mathrm{Me}$ & $\mathbf{1 b}$ & $4-\mathrm{ClPh}$ & $\mathbf{2 a}$ & $\mathbf{3 i}$ & 76 \\
10 & $4-\mathrm{Me}$ & $\mathbf{1 b}$ & $\mathrm{Bn}$ & $\mathbf{2 b}$ & $\mathbf{3 j}$ & 66 \\
11 & $3-\mathrm{Me}$ & $\mathbf{1 b}$ & $\mathrm{Ph}$ & $\mathbf{2 c}$ & $\mathbf{3 k}$ & 65 \\
12 & $4-\mathrm{F}$ & $\mathbf{1 b}$ & $\mathrm{Ph}$ & $\mathbf{2 d}$ & $\mathbf{3 1}$ & 69 \\
13 & $4-\mathrm{F}$ & $\mathbf{1 b}$ & $4-\mathrm{MePh}$ & $\mathbf{2 e}$ & $\mathbf{3 m}$ & 91 \\
14 & $4-\mathrm{F}$ & $\mathbf{1 b}$ & $4-\mathrm{FPh}$ & $\mathbf{2 f}$ & $\mathbf{3 n}$ & 53 \\
15 & $4-\mathrm{F}$ & $\mathbf{1 b}$ & $4-\mathrm{ClPh}$ & $\mathbf{2 h}$ & $\mathbf{3 0}$ & 72 \\
16 & $4-\mathrm{F}$ & $\mathbf{1 c}$ & $\mathrm{Bn}$ & $\mathbf{2 a}$ & $\mathbf{3 p}$ & 54 \\
17 & $4-\mathrm{MeO}$ & $\mathbf{1 d}$ & $4-\mathrm{MePh}$ & $\mathbf{2 a}$ & $\mathbf{3 q}$ & 72 \\
18 & $4-\mathrm{MeO}$ & $\mathbf{1 e}$ & $\mathrm{Ph}$ & $\mathbf{2 a}$ & $\mathbf{3 r}$ & 59 \\
19 & $4-\mathrm{Cl}$ & $\mathbf{1 f}$ & $4-\mathrm{MePh}$ & $\mathbf{2 a}$ & $\mathbf{3 s}$ & 95 \\
& & & & & &
\end{tabular}

${ }^{a}$ Reaction conditions: $1 \mathrm{mmol}$ 1a, $0.5 \mathrm{mmol} 2 \mathrm{a}$, and P4 (0.0038 g), in 20 mL NMP, irradiation with $3 \mathrm{~W}$ blue LED lamp for $6 \mathrm{~h} .{ }^{b}$ Yield after chromatographic purification.

\subsection{The recycled activity of the supported iridium complex}

The recycled activity of $\mathrm{P} 4$ was investigated using the reaction between $N, N$-dimethylaniline (1a) with $N$-phenylmaleimide (2a) (Fig. 4). The catalyst could be recycled by simple centrifugal separation. Then, the recycled $\mathrm{P} 4$ was washed by acetone and the washing solution was also investigated. The results showed

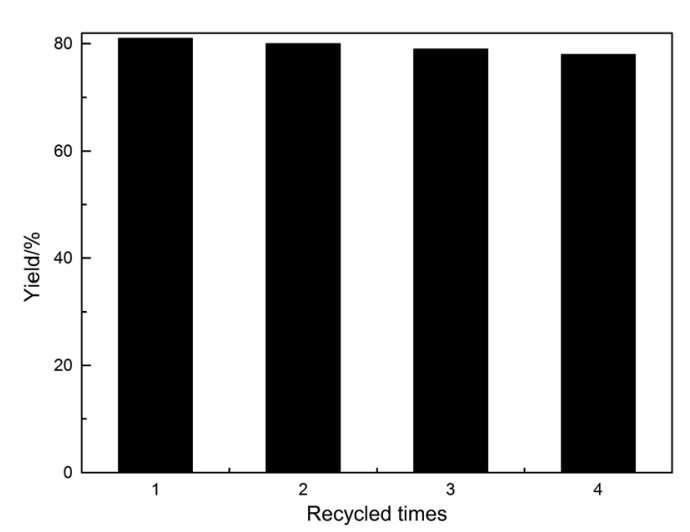

Fig. 4 Catalyst P4 recycling in the visible-light mediated direct cyclization reaction. 


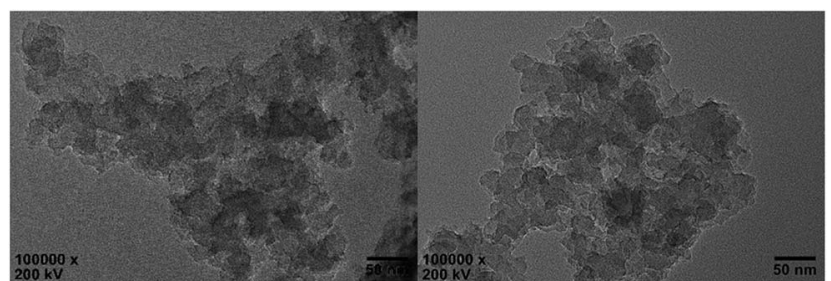

Fig. 5 TEM analyses of P4 before use (left) and after use for four times (right).

that the composition of the washing solution was quite similar to the reaction mixture. The product content was even higher due to the bigger molecule size, which would be adsorbed in the P4 more strongly. Combined with the little catalyst amount, the absorption attached little importance to the yield. The recycled activities showed that P4 owned high stability with the yield decreased little after being recycled for four times. The polymer owned the hypercrosslinked structures with the Ir-complex attached to the supported with more than two bonds, which effectively avoided the active sites releasing and pore blocking. High BET surface area benefited the mass transfer and avoided the carbon deposition. The TEM analysis of the catalyst P4 before and after use for four times also showed no changes, which indicated that the structure was well kept during the catalytic process (Fig. 5).

\section{Conclusions}

The novel supported iridium complex has been synthesized through the immobilization of Ir-complex onto pyridine modified PDVB. The active sites were bidentate chelated, which confirmed the high stability of the catalyst. The catalyst showed high activities for visible light mediated cyclization of tertiary anilines and maleimides. The novel catalyst owned the advantages of high acidity, BET surface, stability and wide application, which made the catalyst hold great potential for the replacement of the homogeneous catalysts in green chemical processes.

\section{Acknowledgements}

This work was supported by the National Natural Science Foundation of China (NSFC 21202101), Zhejiang Provincial Natural Science Foundation of China (LY16B020006) and China Postdoctoral Science Foundation (2015M581919).

\section{Notes and references}

1 M. H. Shaw, J. Twilton and D. W. MacMillan, J. Org. Chem., 2016, 81, 6898-6926.

2 C. K. Prier, D. A. Rankic and D. W. C. MacMillan, Chem. Rev., 2013, 113, 5322-5363.

3 M. Reckenthälera and A. G. Griesbeck, Adv. Synth. Catal., 2013, 355, 2727-2744.
4 K. Teegardin, J. I. Day, J. Chan and J. Weaver, Org. Process Res. Dev., 2016, 20, 1156-1163.

5 M. A. Ischay and T. P. Yoon, Eur. J. Org. Chem., 2012, 18, 3359-3372.

6 J. Xuan and W. J. Xiao, Angew. Chem., Int. Ed., 2012, 51, 682868380.

7 J. R. Chen, X. Q. Hu, L. Q. Lu and W. J. Xiao, Angew. Chem., Int. Ed., 2012, 51, 6828-6838.

8 J. M. R. Narayanam and C. R. J. Stephenson, Chem. Soc. Rev., 2011, 40, 102-113.

9 R. A. Angnes, Z. Li, C. R. D. Correia and G. B. Hammond, Org. Biomol. Chem., 2015, 13, 9152-9167.

10 J. R. Chen, X. Q. Hu, L. Q. Lu and W. J. Xiao, Chem. Soc. Rev., 2016, 45, 2044-2056.

11 G. Pandey, R. Laha and D. Singh, J. Org. Chem., 2016, 81, 7161-7171.

12 L. Shi and W. Xia, Chem. Soc. Rev., 2012, 41, 7687-7697.

13 X. Ju, D. Li, W. Li, W. Yu and F. Bian, Adv. Synth. Catal., 2012, 354, 3561-3567.

14 Z. Liang, S. Xu, W. Tian and R. Zhang, Beilstein J. Org. Chem., 2015, 11, 425-430.

15 S. Zhu, A. Das, L. Bui, H. Zhou, D. P. Curran and M. Rueping, J. Am. Chem. Soc., 2013, 135, 1823-1829.

16 T. P. Nicholls, G. E. Constable, J. C. Robertson, M. G. Gardiner and A. C. Bissember, ACS Catal., 2016, 6, 451-457.

17 M. Nishino, K. Hirano, T. Satoh and M. Miura, J. Org. Chem., 2011, 76, 6447-6451.

18 M. Baghbanzadeh, T. N. Glasnov and C. O. Kappel, J. Flow Chem., 2013, 3, 109-113.

19 T. P. Nicholls, G. E. Constable, J. C. Robertson, M. G. Gardiner and A. C. Bissember, ACS Catal., 2015, 6, 451-457.

20 Z. J. Wang, S. Ghasimi, K. Landfester and K. A. Zhang, Adv. Synth. Catal., 2016, 358, 2576-2582.

21 X. Liu, X. Ye, F. Bureš, H. Liu and Z. Jiang, Angew. Chem., Int. Ed., 2015, 127, 11605-11609.

22 J. Tang, G. Grampp, Y. Liu, B. X. Wang, F. F. Tao, L. J. Wang, X. Z. Liang, H. Q. Xiao and Y. M. Shen, J. Org. Chem., 2015, 80, 2724-2732.

23 J. T. Guo, D. C. Yang, Z. Guan and Y. H. He, J. Org. Chem., 2017, 82, 1888-1894.

24 X. Lang, X. Chen and J. Zhao, Chem. Soc. Rev., 2014, 43, 473486.

25 H. Kisch, Angew. Chem., Int. Ed., 2013, 52, 812-847.

26 D. W. Manley, R. T. McBurney, P. Miller, J. C. Walton, A. Mills and C. O'Rourke, J. Org. Chem., 2014, 79, 13861398.

27 C. Vila and M. Rueping, Green Chem., 2013, 15, 2056-2059.

28 J. Chen, J. Cen, X. Xu and X. Li, Catal. Sci. Technol., 2016, 6, 349-362.

29 D. Friedmann, A. Hakki, H. Kim, W. Choi and D. Bahnemann, Green Chem., 2016, 18, 5391-5411.

30 N. Priyadarshani, Y. Liang, J. Suriboot, H. S. Bazzi and D. E. Bergbreiter, ACS Macro Lett., 2013, 2, 571-574.

31 W. J. Yoo and S. Kobayashi, Green Chem., 2014, 16, 24382442. 
32 D. Rackl, P. Kreitmeier and O. Reiser, Green Chem., 2016, 18, 214-219.

33 D. C. Fabry, M. A. Ronge and M. Rueping, Chem.-Eur. J., 2015, 21, 5350-5354.

34 P. Agrigento, S. M. Al-Amsyar, B. Sorée, M. Taherimehr, M. Gruttadauria, C. Aprile and P. P. Pescarmona, Catal. Sci. Technol., 2014, 4, 1598-1607.

35 Y. Xie, Z. Zhang, T. Jiang, J. He, B. Han, T. Wu and K. Ding, Angew. Chem., Int. Ed., 2007, 119, 7393-7396.

36 F. Liu, L. Wang, Q. Sun, L. Zhu, X. Meng and F. S. Xiao, J. Am. Chem. Soc., 2012, 134, 16948-16950.

37 Y. Zhang, S. Wei, F. Liu, Y. Dua, S. Liu, Y. Ji, T. Yokoi, T. Tatsumi and F.-S. Xiao, Nano Today, 2009, 4, 135-142.

38 X. Liang, H. Xiao and C. Qi, Fuel Process. Technol., 2013, 110, 109-113.
39 S. Santoro, S. I. Kozhushkov, L. Ackermann and L. Vaccaro, Green Chem., 2016, 18, 3471-3493.

40 H. Takeda, M. Ohashi, Y. Goto, T. Ohsuna, T. Tani and S. Inagaki, Adv. Funct. Mater., 2016, 26, 5068-5077.

41 L. Pan, M. Y. Xu, L. J. Feng, Q. Chen, Y. J. He and B. H. Han, Polym. Chem., 2016, 7, 2299-2307.

42 J. A. Johnson, J. Luo, X. Zhang, Y. S. Chen, M. D. Morton, E. Echeverría, F. Torres and J. Zhang, ACS Catal., 2015, 5, 5283-5291.

43 K. Mori, Y. Kubota and H. Yamashita, Chem.-Asian J., 2013, 8, 3207-3213.

44 P. N. Curtin, L. L. Tinker, C. M. Burgess, E. D. Cline and S. Bernhard, Inorg. Chem., 2009, 48, 10498-10506.

45 C. Wang, Z. Xie, K. E. deKrafft and W. Lin, ACS Appl. Mater. Interfaces, 2012, 4, 2288-2294. 